Available online at www.sciencedirect.com

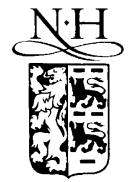

ELSEVIER

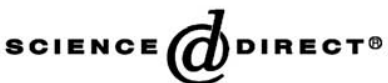

Surface Science 532-535 (2003) 396-401
SURFACE SCIENCE

$\overline{\overline{\text { elsevier.com/locate/susc }}}$

\title{
Interaction of oxygen with chromium deposited on $\mathrm{Al}_{2} \mathrm{O}_{3} / \mathrm{NiAl}\left(\begin{array}{lll}1 & 1 & 0\end{array}\right)$
}

\author{
J. Sainio *, M. Eriksson, J. Lahtinen \\ Laboratory of Physics, Helsinki University of Technology, P.O. Box 1100, 02015 Hut, Finland
}

\begin{abstract}
We have investigated the growth and reactivity of chromium layers deposited onto a thin alumina film at room temperature and at $570 \mathrm{~K}$. The interaction between $\mathrm{Cr}$ and the $\mathrm{Al}_{2} \mathrm{O}_{3} / \mathrm{NiAl}\left(\begin{array}{lll}1 & 1 & 0\end{array}\right)$ surface leads to partial oxidation to $\mathrm{Cr}^{2+}$ and $\mathrm{Cr}^{3+}$ species. Complete oxidation to $\mathrm{Cr}^{3+}$ was achieved using moderate $\mathrm{O}_{2}$ doses at room temperature in vacuum. $\mathrm{Cr}$ has also been deposited in an $\mathrm{O}_{2}$ background pressure of $1.4 \times 10^{-6}$ Torr. The development of the XP spectra after deposition in $\mathrm{O}_{2}$ suggests that chromium oxide catalyzes the oxidation of aluminum atoms below the thin otherwise inert alumina film. Our results also show that deposition of chromium on $\mathrm{Al}_{2} \mathrm{O}_{3} / \mathrm{NiAl}\left(\begin{array}{lll}1 & 1 & 0\end{array}\right)$ at $570 \mathrm{~K}$ leads to significantly larger clusters than at room temperature as indicated by the incomplete oxidation of $\mathrm{Cr}$.
\end{abstract}

(C) 2003 Elsevier Science B.V. All rights reserved.

Keywords: X-ray photoelectron spectroscopy; Chromium; Aluminum oxide; Single crystal epitaxy; Catalysis

\section{Introduction}

Supported chromium oxide catalysts used in dehydrogenation of alkanes investigated by XPS have been the subject of numerous studies, e.g. by Cavani et al. [1] and Kytökivi et al. [2] and references therein. Impregnated catalysts show two main chromium oxidation states, +3 and +6 . At coverages well below one monolayer $\mathrm{Cr}$ is found in the +6 oxidation state, but the amount of $\mathrm{Cr}^{3+}$ increases with chromium coverage. Some of the formed +3 species cannot be oxidized further, which has been claimed to indicate incorporation of $\mathrm{Cr}$ in the alumina lattice. However, obtaining

\footnotetext{
${ }^{*}$ Corresponding author. Tel.: +358-9-451-3130; fax: +358-9451-3116.

E-mail address: jani.sainio@hut.fi (J. Sainio).
}

information on the catalyst structure from these impregnated catalysts is difficult.

Metal and oxide particles grown on oxidized single crystal surfaces provide a controlled approach to the understanding of surface reactions on oxide catalysts. Proper oxidation of the NiAl(lllll 10$)$ alloy single crystal results in a thin, well-ordered alumina film with a surface structure reminiscent of bulk $\gamma-\mathrm{Al}_{2} \mathrm{O}_{3}$ [3]. The ordering of the film gives us the possibility to study basic surface reactions e.g. to determine the adsorption sites of catalytically relevant gases. Palladium supported on $\mathrm{Al}_{2} \mathrm{O}_{3} / \mathrm{NiAl}\left(\begin{array}{lll}1 & 1 & 0\end{array}\right)$ was recently found to be catalytically very active in ethylene hydrogenation to ethane [4] indicating the relevance of this type of model catalyst studies.

Deposition of several noble and transition metals on the $\mathrm{Al}_{2} \mathrm{O}_{3} / \mathrm{NiAl}\left(\begin{array}{lll}1 & 1 & 0\end{array}\right)$ surface have been studied (see Ref. [5] for a review). The growth of 
the metal layer exhibit formation of 3D particles close to Volmer-Weber (VW) fashion in most of the systems, like V, Rh, Co and Pd. Platinum has received the most intense attention and it has been found to grow two-dimensionally with the Pt particles modifying the structure of the support $[6,7]$.

We have previously studied the growth of $\mathrm{Cr}$ on $\mathrm{Al}_{2} \mathrm{O}_{3} / \mathrm{NiAl}\left(\begin{array}{lll}1 & 1 & 0\end{array}\right)$ at room temperature [8]. In this paper we focus on the growth and reactive properties of $\mathrm{Cr}$ deposited on the thin alumina film. $\mathrm{Cr}$ was deposited from the vapor phase at two sample temperatures, 300 and $570 \mathrm{~K}$. Cr was also deposited in an oxygen background pressure. The chromium and chromium oxide films were characterized using X-ray photoelectron spectroscopy (XPS). The growth mode dependence on temperature was observed by the change in oxidation state distribution in the samples both after evaporation and after oxidation.

\section{Experimental}

The experiments reported in this paper were performed in a stainless steel UHV chamber with a base pressure of $2 \times 10^{-10}$ Torr. The sample cleanliness was measured and the surface characterization was performed with XPS using a double pass cylindrical mirror analyzer. Both $\mathrm{A} 1 \mathrm{~K} \alpha$ and $\mathrm{Mg} \mathrm{K} \alpha$ radiation were used in the XPS measurements and the binding energy scale was calibrated using the $\mathrm{Ni} 2 \mathrm{p}_{3 / 2}$ and $\mathrm{Ni} 3 \mathrm{p}$ peaks at 852.7 and $66.5 \mathrm{eV}$, respectively [9].

Cleaning of the $\mathrm{NiAl}(110)$ sample was performed using $3 \mathrm{keV} \mathrm{Ar}^{+}$ion sputtering with $25 \mu \mathrm{A}$ emission for $60 \mathrm{~min}$ at room temperature. Sputtering was continued at $700 \mathrm{~K}$ for $30 \mathrm{~min}$. Subsequent annealing at $1150 \mathrm{~K}$ for $45-60$ min gave a sharp $(1 \times 1)$ LEED pattern of the NiAl( $\left.\begin{array}{lll}1 & 1 & 0\end{array}\right)$ surface.

Formation of the thin, well-ordered alumina film was performed by exposing the clean and annealed $\mathrm{NiAl}\left(\begin{array}{lll}1 & 1 & 0\end{array}\right)$ crystal to $3600 \mathrm{~L}\left(1 \mathrm{~L}=10^{-6}\right.$ Torr s) of $\mathrm{O}_{2}$ at $550 \mathrm{~K}$ followed by annealing for 3 $\min$ at $1150 \mathrm{~K}$. More information on this procedure has been given elsewhere $[3,10]$. The appearance of the rather complicated LEED pattern associated with the ordered alumina film [3] was used as a measure of the correct surface structure.
Chromia/alumina model systems were prepared by evaporating metallic $\mathrm{Cr}$ onto the well-ordered $\mathrm{Al}_{2} \mathrm{O}_{3} / \mathrm{NiAl}\left(\begin{array}{lll}1 & 1 & 0\end{array}\right)$ surface. Background pressure in the UHV chamber was below $2 \times 10^{-9}$ Torr during evaporation. The layer growth was controlled by adjusting the evaporation time and current of the chromium evaporator.

\section{Results and discussion}

\subsection{Metal-alumina interaction}

After forming the ordered alumina film we deposited $\mathrm{Cr}$ on the surface at room temperature and at $570 \mathrm{~K}$. The deposition rate was evaluated in our previous study by measuring the $2 \mathrm{p}$ photoelectron signals of $\mathrm{Cr}$ and $\mathrm{Ni}$ as functions of deposition time (XS- $t$ plot) at room temperature yielding a deposition rate of $(3.4 \pm 0.2) \times 10^{12} \mathrm{Cr} / \mathrm{cm}^{2} \mathrm{~s}$ [8].

In our estimation of the coverages for the $570 \mathrm{~K}$ deposition we assume that the sticking coefficient is the same at room temperature and $570 \mathrm{~K}$. We are aware that for Ag on alumina a decrease in the initial sticking coefficient of $50 \%$ has been observed when increasing temperature from 300 to $500 \mathrm{~K}$ [11]. The sticking coefficient of $\mathrm{Cr}$ is also likely to decrease somewhat in the used temperature range, resulting in lower actual coverages for the $570 \mathrm{~K}$ deposition. This would not however change the interpretation of the oxidation states.

In our experiments we used three nominal coverages, $6.8 \times 10^{14}, 1.4 \times 10^{15}$ and $2.0 \times 10^{15} \mathrm{Cr}$ at. $/ \mathrm{cm}^{2}$ corresponding to deposition times of 200 , 400 and $600 \mathrm{~s}$. The topmost oxygen layer of the alumina film has an oxygen atom density of $1.27 \times 10^{15}$ at. $/ \mathrm{cm}^{2}$ [3]. If this number is used as a reference for one monolayer the $\mathrm{Cr}$ coverages are $0.54,1.1$ and 1.6 ML. The coverages presented here are estimates only since no other method was used to evaluate the coverage.

After evaporation the $\mathrm{Cr} 2 \mathrm{p}, \mathrm{Al} 2 \mathrm{p}$ and $\mathrm{O} 1 \mathrm{~s} \mathrm{XP}$ spectra were measured. The decomposition of the Cr $2 p$ XP spectra was done by fitting doublet peaks for all the chromium oxidation states after Tougaard background subtraction [12,13] using the binding energy values given in our previous study [8]. One metallic component and two 
oxidized components, $\mathrm{Cr}^{3+}$ and $\mathrm{Cr}^{2+}$, are sufficient to explain the observed spectra. A shake-up satellite was used in the analysis for the $\mathrm{Cr}^{3+}$ doublet $4.1 \mathrm{eV}$ above the main line.

Fig. 1 shows the Cr $2 p$ XP spectra for a nominal coverage of $20 \mathrm{Cr} / \mathrm{nm}^{2}$ after deposition at room temperature and at $570 \mathrm{~K}$. A small shift towards lower binding energy is observed for the $\mathrm{Cr} 2 p$ emission after deposition at elevated temperature, which could be due to an increase in metallic $\mathrm{Cr}$. Both $\mathrm{Cr}^{3+}$ and $\mathrm{Cr}^{2+}$ are also present after deposition at $570 \mathrm{~K}$, but the fraction of $\mathrm{Cr}^{3+}$ is smaller than after the deposition at room temperature. The shift towards lower binding energy could also be due to final state effects. It is known that for metals on inert surfaces the binding energy increases with decreasing cluster size. This effect has been observed for $\mathrm{Pd}$ on $\mathrm{Al}_{2} \mathrm{O}_{3} / \mathrm{NiAl}\left(\begin{array}{lll}1 & 1 & 0\end{array}\right)$ [14]. We however did not observe any significant change in the binding energy of the $\mathrm{Cr} 2 \mathrm{p}$ metallic component as a function of coverage. In this view

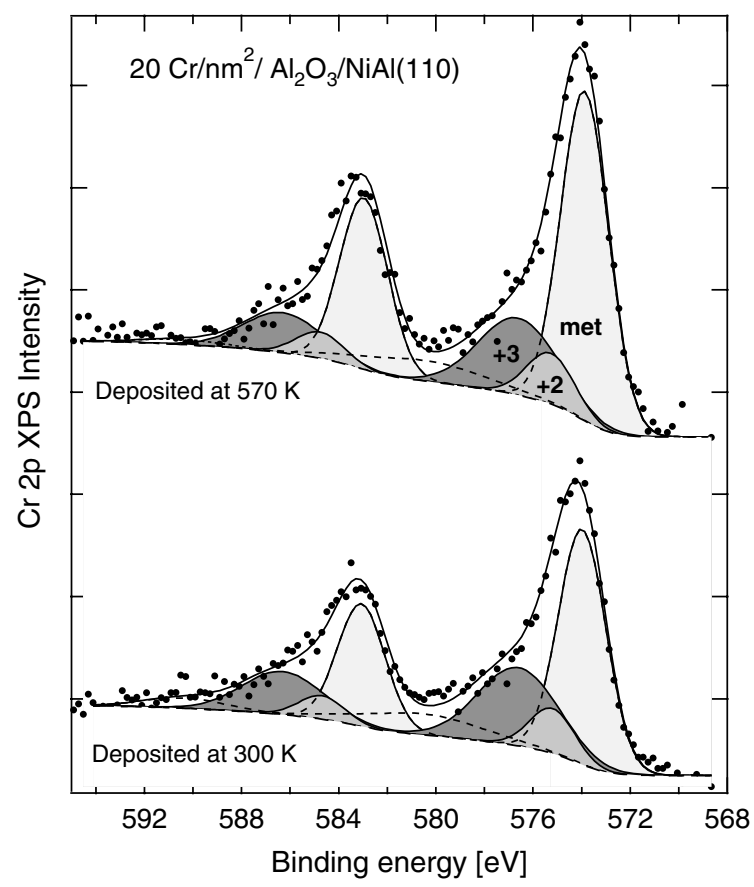

Fig. 1. Cr $2 p$ XP spectra of chromium deposited onto the $\mathrm{Al}_{2} \mathrm{O}_{3} / \mathrm{NiAl}\left(\begin{array}{lll}1 & 1 & 0\end{array}\right)$ surface at room temperature and at $570 \mathrm{~K}$. The oxidation states are indicated in the figure. The spectra have been normalized to constant area of decomposed peaks. Measurements were performed at room temperature. it should be safe to say that final state effects are in this case sufficiently small not to have a significant effect on the interpretation of the XP spectra. A general decrease in the $\mathrm{Cr} 2 \mathrm{p}$ signal was also observed for the deposition at $570 \mathrm{~K}$ compared to the room temperature experiments. This decrease could be due to an increase in the cluster size or a decrease in the sticking coefficient. Only a small attenuation in the $\mathrm{Ni} 2 \mathrm{p}_{3 / 2}$ peak was seen following $\mathrm{Cr}$ deposition at elevated temperature, which suggests $3 \mathrm{D}(\mathrm{VW})$ growth. The attenuation in the $\mathrm{Ni} 2 \mathrm{p}_{3 / 2}$ peak was much more pronounced after deposition at room temperature.

The oxidation state distribution of chromium after deposition is shown in Table 1. Compared to the room temperature deposition, a clear increase in the metallic component is observed for all coverages corresponding to a decrease in the $\mathrm{Cr}^{3+}$ component. The amount of $\mathrm{Cr}^{2+}$, on the other hand, stays almost constant. The presence of $\mathrm{Cr}^{2+}$ and $\mathrm{Cr}^{3+}$ in the as deposited films at both temperatures supports the idea that these states are due to the initial interaction between $\mathrm{Cr}$ and the $\mathrm{Al}_{2} \mathrm{O}_{3} / \mathrm{NiAl}\left(\begin{array}{lll}1 & 1 & 0\end{array}\right)$ support. However, we are not able to differentiate the origin of these chemical states.

\subsection{Interaction with gas phase oxygen}

When the chromium overlayer was oxidized by $20 \mathrm{~L}\left(1 \mathrm{~L}=10^{-6}\right.$ Torr s) of $\mathrm{O}_{2}$, chromium grown at room temperature was totally oxidized to $\mathrm{Cr}^{3+}$ species at all coverages. The $\mathrm{Cr}$ clusters formed at $570 \mathrm{~K}$ however are not completely oxidized, even if higher oxygen exposures are used.

Table 1

Oxidation state distribution for $\mathrm{Cr}$ after deposition at room temperature and at $570 \mathrm{~K}$

\begin{tabular}{lccl}
\hline$\left(\mathrm{Cr} / \mathrm{nm}^{2}\right)$ & $\mathrm{Cr}^{0}[\%]$ & $\mathrm{Cr}^{2+}[\%]$ & $\mathrm{Cr}^{3+}[\%]$ \\
\hline \multicolumn{2}{l}{ Deposited at } & room temperature & \\
6.8 & 34 & 13 & 53 \\
14 & 40 & 15 & 45 \\
20 & 49 & 13 & 38 \\
\multicolumn{5}{l}{ Deposited } & at & $570 \mathrm{~K}$ & & \\
6.8 & 45 & 14 & 41 \\
14 & 53 & 14 & 33 \\
20 & 60 & 10 & 30 \\
\hline
\end{tabular}




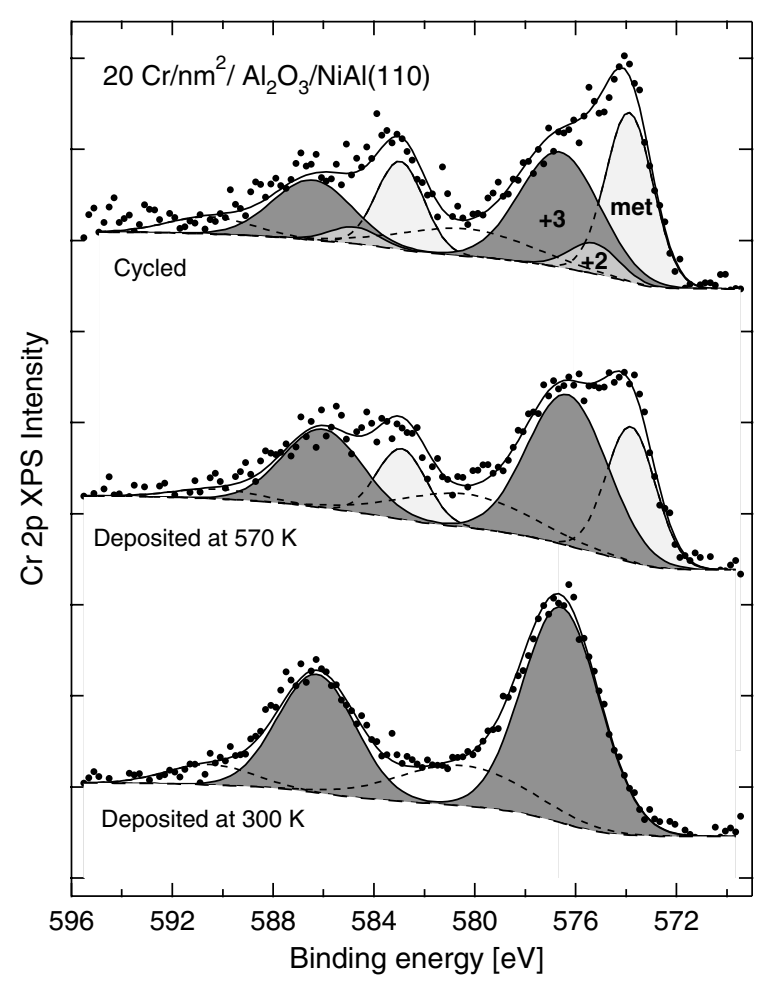

Fig. 2. Cr $2 p$ XP spectra of oxidized chromium layers after deposition onto the $\mathrm{Al}_{2} \mathrm{O}_{3} / \mathrm{NiAl}\left(\begin{array}{lll}1 & 1 & 0\end{array}\right)$ surface at room temperature and at $570 \mathrm{~K}$. The topmost curve corresponds to a 570 $\mathrm{K}$ deposited sample after an oxidation-reduction-oxidation cycle. The oxidation states are indicated in the figure. The spectra are normalized to constant area of decomposed peaks. Measurements were performed at room temperature.

The difference in chromium oxidation can be seen in Fig. 2, which shows Cr 2p XP spectra after oxidation for both deposition temperatures for a nominal coverage of $20 \mathrm{Cr} / \mathrm{nm}^{2}$. Only one chemical state is needed for the room temperature deposited sample but a metallic component is still clearly visible after oxidation in the sample deposited at $570 \mathrm{~K}$. The component corresponding to the $\mathrm{Cr}^{2+}$ state was not needed, but the fit is quite insensitive for concentrations below 5\%. Small amounts of $\mathrm{Cr}^{2+}$ could therefore be present in the sample even after oxidation.

Table 2 shows the oxidation state distribution for the three coverages deposited at $570 \mathrm{~K}$ after exposure to $20 \mathrm{~L}$ of $\mathrm{O}_{2}$. The concentration of metallic $\mathrm{Cr}$ is independent of the coverage implying that the shape of the clusters does not change
Table 2

Oxidation state distribution for chromium layers deposited at $570 \mathrm{~K}$ on $\mathrm{Al}_{2} \mathrm{O}_{3} / \mathrm{NiAl}\left(\begin{array}{lll}1 & 1 & 0\end{array}\right)$ after oxidation and after a subsequent reduction-oxidation cycle

\begin{tabular}{lccl}
\hline$\left(\mathrm{Cr} / \mathrm{nm}^{2}\right)$ & $\mathrm{Cr}^{0}[\%]$ & $\mathrm{Cr}^{2+}[\%]$ & $\mathrm{Cr}^{3+}[\%]$ \\
\hline Deposited at & 570 K and oxidized \\
6.8 & 29 & - & 71 \\
14 & 30 & - & 70 \\
20 & 28 & - & 72 \\
\multicolumn{5}{r}{ Subsequently } & reduced and re-oxidized \\
6.8 & 33 & 5 & \\
14 & 36 & 12 & 62 \\
20 & 37 & 8 & 52 \\
\hline
\end{tabular}

Our estimate for the error is $\pm 5 \%$.

significantly during growth. Based on the incomplete oxidation of the clusters deposited at $570 \mathrm{~K}$ it is obvious that they differ in shape and size when compared to the clusters formed at room temperature.

When single crystal $\mathrm{Cr}\left(\begin{array}{lll}1 & 1 & 0\end{array}\right)$ samples have been oxidized at room temperature [15], the extent of oxidation has been reported to be only about $10 \AA$ into the sample. In our experiments with chromium deposited at $570 \mathrm{~K}$ the metallic component is still clearly visible after oxidation. In this view it is safe to say that the cluster size should exceed 20 $\AA$, even though no exact measure can be given. On the other hand, chromium grown at room temperature forms smaller and/or flatter clusters. For vanadium, which is also an early transition metal, the island diameters were found to be around 20$30 \AA$ when grown at room temperature [16]. STM images suggested that some of the deposited vanadium was incorporated in the alumina film with XPS showing partial oxidation of the metal. Similar growth behavior and cluster sizes could be expected for chromium at room temperature.

The oxidized chromium layers can be thermally reduced by heating the sample to $700 \mathrm{~K}$ for $5 \mathrm{~min}$. This produces an oxidation state distribution similar to the one after deposition. Re-oxidation of room temperature grown samples leads to solely $\mathrm{Cr}^{3+}$ species as before. Chromium grown at $570 \mathrm{~K}$ shows changes if the sample is re-oxidized after this reduction. The oxidation state distribution for the $570 \mathrm{~K}$ grown samples after one oxidationreduction-oxidation cycle is given in Table 2 . 
A clear increase in the metallic component is observed compared to the first oxidation, which can be seen in Fig. 2. Also the $\mathrm{Cr}^{2+}$ component could not be excluded from the fit anymore. This rather surprising behavior must be due to growth in the chromium cluster size. No evidence of the $\mathrm{Cr}^{6+}$ state was found following the treatments described.

The oxidation state distribution does not change if a second reduction-oxidation cycle is carried out. The chromium clusters have reached their equilibrium shape, showing that the growth at room temperature is indeed kinetically limited. Most transition metals exhibit formation of 3Dparticles on the $\mathrm{Al}_{2} \mathrm{O}_{3} / \mathrm{NiAl}\left(\begin{array}{lll}1 & 1 & 0\end{array}\right)$ surface, which seems the most likely growth mode for $\mathrm{Cr}$ as well. Whether nucleation is heterogeneous or homogeneous cannot be distinguished without e.g. STM measurements.

\subsection{Changes in the substrate alumina film}

During the experiments we observed a severe disruption of the self-terminating growth of the alumina film, when chromium was added to the system. For vanadium on $\mathrm{Al}_{2} \mathrm{O}_{3} / \mathrm{NiAl}\left(\begin{array}{lll}1 & 1 & 0\end{array}\right)$, a thickening of the alumina film has been observed when vanadium has been deposited in an $\mathrm{O}_{2}$ partial pressure of $7 \times 10^{-7}$ Torr at $725 \mathrm{~K}$ [16]. A similar thickening process was observed with chromium in this work.

The alumina film is known to be very inert and the pure film does not show any changes with oxygen treatments performed at temperatures below $800 \mathrm{~K}$ [3]. To study the effect of chromium on the thickening of the film we deposited $\mathrm{Cr}$ in a oxygen pressure of $1.4 \times 10^{-6}$ Torr at a substrate temperature of $570 \mathrm{~K}$. The chromium coverage was $14 \mathrm{Cr} / \mathrm{nm}^{2}$.

The $\mathrm{Al} 2 \mathrm{p}$ and the Ni $3 p$ signals are shown in Fig. 3 for the clean alumina film and after deposition of $\mathrm{Cr}$ in $\mathrm{O}_{2}$ background pressure. The $\mathrm{Al} 2 \mathrm{p}$ signal consists of a metallic component from the bulk NiAl alloy and an aluminum oxide component at a slightly higher binding energy.

A significant increase in the aluminum oxide $2 p$ signal is observed after the deposition, but the total Al signal remains quite constant. The Ni $3 p$ signal,

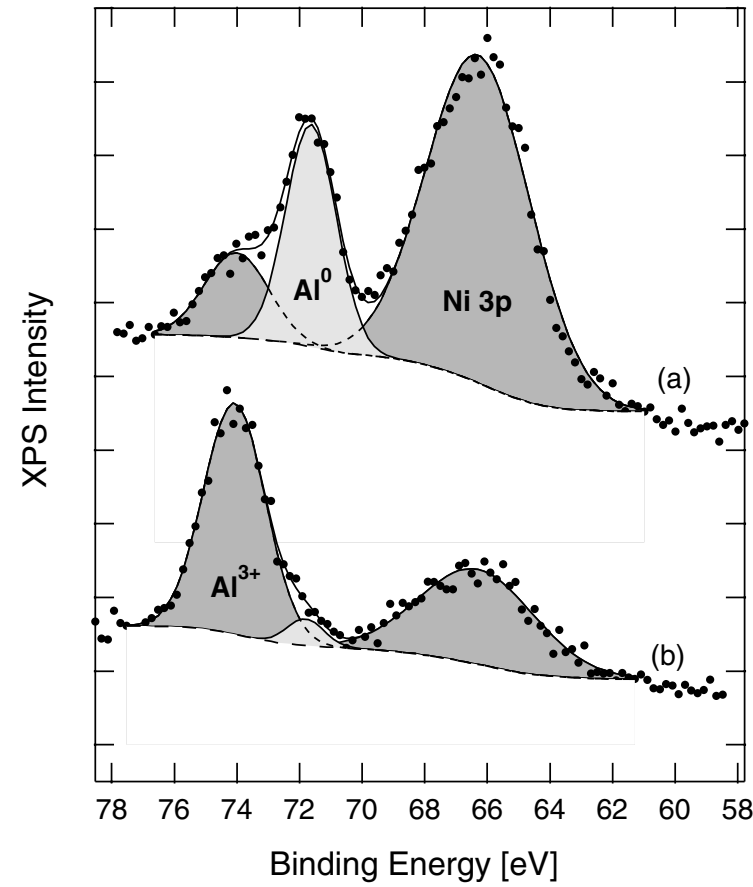

Fig. 3. Al $2 p$ and Ni $3 p$ XP spectra of the model catalyst before (a) and after (b) deposition of $14 \mathrm{Cr} / \mathrm{nm}^{2}$ chromium in an oxygen background pressure of $1.4 \times 10^{-6}$ Torr. A clear increase in the $\mathrm{Al}^{3+}$ component is observed after deposition showing thickening of the aluminum oxide film.

on the other hand, decreases significantly. Measurements of the $\mathrm{O} 1 \mathrm{~s}$ intensity show an overall increase in oxygen emission. Combining these observations of XP spectra we propose a mechanism of oxide growth where $\mathrm{O}_{2}$ dissociation is catalyzed by chromium. The oxygen atoms then diffuse trough the oxide layer and react with $\mathrm{Al}$. We were also able to confirm that this reaction takes place even at room temperature although the effect is far more dominant at elevated temperature.

The same reaction can also be observed during the thermal reduction of the samples. Using a mass spectrometer we were able to show that no oxygen is desorbed when the chromium layers are heated to $700 \mathrm{~K}$ after oxidation. A shift in the $\mathrm{O} 1 \mathrm{~s}$ signal toward higher binding energies is observed after this heating indicating an increase in the fraction of aluminum oxide. Hence, the thermal reduction of chromium leads to an increased amount of aluminum oxide. 


\section{Conclusions}

We have studied the growth of chromium on $\mathrm{Al}_{2} \mathrm{O}_{3} / \mathrm{NiAl}\left(\begin{array}{lll}1 & 1 & 0\end{array}\right)$ at substrate temperatures of 300 and $570 \mathrm{~K}$. Our results suggest that at $570 \mathrm{~K} \mathrm{Cr}$ grows in a Volmer-Weber like 3D-mode. At room temperature the growth is kinetically limited leading to smaller and/or flatter clusters. Chromium also acts as a catalyst on the surface for $\mathrm{O}_{2}$ dissociation leading to a clear thickening of the alumina film especially at elevated temperatures.

The clusters formed at $570 \mathrm{~K}$ are similar in oxidation state distribution as clusters formed at room temperature. The metallic $\mathrm{Cr}$ component is dominant, but both $\mathrm{Cr}^{3+}$ and $\mathrm{Cr}^{2+}$ species are found on the surface. The partial oxidation is due to the initial interaction between the deposited chromium atoms and the oxygen terminated alumina film.

Chromium grown at room temperature can be totally oxidized to $\mathrm{Cr}^{3+}$ species at all coverages used. Exposure of clusters grown at $570 \mathrm{~K}$ to oxygen leads to incomplete oxidation of $\mathrm{Cr}$, indicating a clear increase in cluster size. The clusters formed at $570 \mathrm{~K}$ reach their equilibrium shape after subsequent heating to $700 \mathrm{~K}$.

No indications of higher oxidation states than +3 for chromium were found following the treatments described in this work, although higher oxidation states, mainly $\mathrm{Cr}^{6+}$, are present in industrial chromium catalysts.

\section{Acknowledgements}

This work was supported by the Academy of Finland. J. Sainio gratefully acknowledges the financial support of the Finnish Academy of Science and Letters. We also acknowledge the fruitful discussions with the groups of professor Outi Krause and professor Markku Räsänen.

\section{References}

[1] F. Cavani, M. Koutyrev, F. Trifir, A. Bartolini, D. Ghisletti, R. Iezzi, A. Santucci, G. Del Piero, J. Catal. 158 (1996) 236.

[2] A. Kytökivi, J.-P. Jacobs, A. Hakuli, J. Meriläinen, H.H. Brongersma, J. Catal. 162 (1996) 190.

[3] R.M. Jaeger, H. Kuhlenbeck, H.-J. Freund, M. Wuttig, W. Hoffman, R. Franchy, H. Ibach, Surf. Sci. 259 (1991) 235.

[4] G. Rupprechter, H. Unterhalt, M. Morkel, P. Galletto, L. Hu, H.-J. Freund, Surf. Sci. 502-503 (2002) 109.

[5] M. Bäumer, H.-J. Freund, Prog. Surf. Sci 61 (1999) 127.

[6] S.A. Nepijko, M. Klimenkov, H. Kuhlenbeck, D. Zymlyanov, D. Herein, R. Schlögl, H.-J. Freund, Surf. Sci. 412/ 413 (1998) 192.

[7] S.A. Nepijko, M. Klimenkov, M. Adelt, H. Kuhlenbeck, R. Schlögl, H.-J. Freund, Langmuir 15 (1999) 5309.

[8] M. Eriksson, J. Sainio, J. Lahtinen, J. Chem. Phys. 116 (2002) 3870

[9] J. Chastain (Ed.), Handbook of X-ray Photoelectron Spectroscopy, Physical Electronics, Inc., USA, 1992.

[10] J. Libuda, F. Winkelmann, M. Bäumer, H.-J. Freund, Th. Bertrams, H. Neddermeyer, K. Müller, Surf. Sci. 318 (1994) 61.

[11] D.G. Van Campen, J. Hrbek, J. Phys. Chem. 99 (1995) 16389.

[12] M.P. Seah, I.S. Gilmore, S.J. Spencer, Surf. Sci. 461 (2000) 1.

[13] J.J. Weimer, http://lmass.uah.edu/software/. The analysis was performed using the SpXZeigR routines under the Igor program.

[14] A. Sandell, J. Libuda, P.A. Brühwiler, S. Andersson, M. Bäumer, A.J. Maxwell, N. Mårtenson, H.-J. Freund, Phys. Rev. B 55 (1997) 7233.

[15] V. Maurice, S. Cadot, P. Marcus, Surf. Sci. 458 (2000) 195.

[16] M. Bäumer, J. Beinder, R.J. Madix, Surf. Sci. 432 (1999) 189. 